\title{
Research on the Problems and Suggestions for the Development of Management Accounting in China Under the Background of " the Belt and Road Initiatives "
}

\begin{abstract}
Lu Jingyan
Department of management, ShanDong University, WeiHai, China

2682192149@qq.com

ABSTRACT

The implementation of " the Belt and Road Initiatives " strategy provides a good opportunity for Chinese enterprises to go abroad. However, opportunities often coexist with risks. As enterprises move toward the international stage, they will also be exposed to a more complex and volatile business environment and face higher operating risks. Management accounting can provide information support for the operating decision-making of enterprises and help them avoid operating risks. In the context of the implementation of " the Belt and Road Initiatives " strategy, management accounting will play an increasingly important role. This article discusses the opportunities and problems faced by the development of management accounting in China. We should seize the opportunities brought by the implementation of " the Belt and Road Initiatives " strategy to promote the development of management accounting both in theory and practice. Finally, this article gives corresponding countermeasures and suggestions for the problems of management accounting under the background of " the Belt and Road Initiatives ".
\end{abstract}

Keywords: The Belt and Road Initiatives, Management Accounting, Problem and Solution

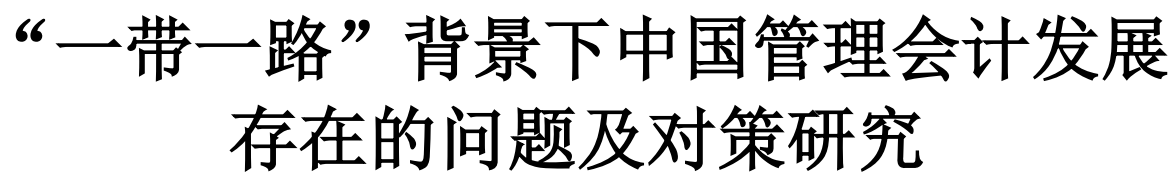

卢京艳

山东大学管理学系, 威海, 中国

2682192149@qq.com

\section{摘要}

“一带一路” 战略的实施为我国企业走出国门走向世界提供了良好的机遇。然而机遇往往与风险并存，企业 在走向国际舞台的同时也会置身于更加复杂多变的经营环境中, 面临着更高的经营风险。在复杂多变的海外环 境中，管理会计可以为企业的经营决策提供信息支持，规避经营风险。因此，在 “一带一路” 战略实施的背景 下管理会计将会发挥着越来越重要的作用。本文从“一带一路” 战略实施的背景出发，分别对我国管理会计发 展面临的机遇以及存在的问题展开了探讨。我国管理会计应当抓住 “一带一路” 战略实施带来的发展机遇，推 进管理会计理论与实践的发展。最后本文针对管理会计在 “一带一路” 发展背景下存在的问题给出了相应的对 策建议。

关键词: “一带一路”; 管理会计; 问题对策 


\section{1. 前言}

“一带一路”的战略构想是由习近平主席在 2013 年访问中亚与东南亚期间首次提出。其中 “一带” 是 指建设 “丝绸之路经济带” , “一路” 是指建设 “21 世纪海上丝绸之路”，“一带一路”倡议所涉及国家 众多，铺设了我国与太平洋、印度洋沿岸国家之间的 贸易带。该倡议自提出以来便得到沿线相应国家的积 极回应以及国际上的高度关注。可以说这是我国在 21 世纪提出的最为关键的一项国际战略。“一带一路” 倡议的提出是为了促进高效的资源配置、经济要素的 有序自由流动, 推动沿线国家更为积极的合作, 从而 使得各个国家进一步发展成为文化包容、政治互信、 互惠互利的合作伙伴。在此背景下, 我国企业与相应 国家间的贸易往来和投资合作日益密切, 越来越多的 企业选择 “走出去”, 这毫无疑问对我国经济发展起 到了促进作用。这也为我国企业的发展带来了前所未 有的机遇，而机遇与挑战并存，企业在抓住机遇的同 时也要积极创新应对挑战。“一带一路” 背景下, 由于 各国文化差异、政策风险等诸多原因, 选择走出国门 的企业将会不可避免的面临更加复杂的经营环境和 更高的经营风险。管理会计作为企业创造价值的重要 工具, 在企业的经营决策等各个方面所发挥的作用不 容忽视。在企业走向国际舞台的同时, 新的时代背景 也对企业管理会计的应用与创新做出了新的要求。因 此在 “一带一路” 不断推行的大趋势下, 我们要抓住 机遇对管理会计进行创新发展, 以便帮助我国企业在 走向世界舞台的同时拥有更强的竞争力。

\section{2. 一带一路为企业管理会计发展带来的机遇}

\section{1. “一带一路”背景下国家政策的大力支持 为管理会计发展提供契机}

“一带一路”战略实施后的 2014 年 10 月 27 日, 我国财政部印发《关于全面推进管理会计体系建设的 指导意见》。该意见强调了全面推进管理会计体系建 设的重要性与紧迫性, 并提出了 “建立与我国社会主 义市场经济体制相适应的管理会计体系” 的主要目标。 在 2016 年 6 月发布了《管理会计基本指引》, 在管理 会计指引体系中起统领作用。同年十月份又发布了 《会计改革与发展 “十三五” 规划纲要》, 纲要对推进 管理会计广泛应用做出了明确指示, 要求加强管理会 计的国际交流与合作, 从而使得我国管理会计发展在 国际管理会计界的影响力和地位得到不断地提高。之 后又于 2017 年推出多项《管理会计应用指引》。可见 随着 “一带一路” 政策的实施, 我国相关部门越来越 重视管理会计的发展, 这一系列的政策指引无疑为管 理会计的创新发展指明了道路, 使得管理会计在我国 的发展进程得到极大的推进。“一带一路” 战略在推 动我国企业投资决策、风险管理以及成本预算等方面 发挥着重要作用。这正是我国管理会计得到进一步发 展的契机。在 “一带一路” 战略实施的背景下, 管理 会计将会发挥更加重要的经济作用。我国企业在相关
政策指引下, 通过对管理会计工具的恰当使用提高自 身的管理水平与经济效益, 从而促进经济更好发展。

\section{2. “一带一路”战略的实施为管理会计发展 提供了开阔的发展平台}

“一带一路”本身建设的重点内容便是加强沿线 国家的投资贸易合作，通过各国间的友好合作来实现 投资贸易的便利化, 从而在区域内创造出良好的营商 环境, 各国互惠互利, 合作共赢。一方面, “一带一路” 的建设为管理会计人才交流提供契机。在这个背景下, 我国企业在走出国门的同时势必会加强与国外企业 间的交流与合作，这便为企业间的管理会计人才交流 与培养提供了良好的平台。不同国家地区间的企业可 以进行管理会计人才培养的交流与借鉴, 从而加快我 国管理会计人才的培养进程, 也有利于培养出一批具 有国际视野的管理会计人才, 共同推动管理会计实践 的应用发展。而管理会计实践的应用与发展必将推动 我国管理会计理论研究的创新与进步, 为中国特色管 理会计理论体系的建成贡献力量。另一方面, 为不同 国家间经营管理模式的相互借鉴提供了平台。”一带 一路 “沿线经过六十多个国家，各个国家不同的政治 经济文化等发展水平导致各国管理会计理念以及发 展水平的不同。管理会计在实际应用时应当本着为企 业创造价值的目标, 结合企业本身的特点来进行个性 化的设计。相应的不同国家企业的经营管理制度方面 自然也存在差异。对此我国企业在与沿线国家进行交 流合作的同时也应当积极的学习借鉴其经营管理模 式, 以此来完善自身经营管理中存在的不足。管理会 计与企业的日常经营管理活动息息相关，可见”一带 一路 “的建设为此提供了良好的契机。在此契机下, 我国管理会计可以吸收借鉴国际先进经验, 结合中国 国情, 形成具有中国特色的管理会计理论体系。

当然, 机遇与风险并存。随着 “一带一路” 建设 的推进, 我国企业迎来国际化发展契机的同时也会遇 到相应的风险。比如不同国家间的体制政策风险、因 为社会以及法律等影响导致的管理风险, 这些都会影 响到企业的经营决策。管理会计的主要职能便包括帮 助企业提高其内部的经营管理水平从而为企业创造 价值提高其经济利益。为了应对 “一带一路” 背景下 企业外部经营环境改变所带来的经营风险, 管理会计 的创新与发展刻不容缓。

\section{3. “一带一路” 背景下我国企业管理会计发展 存在的问题}

\section{1. 我国管理会计发展概述}

我国在上世纪七十年代末开始引入了管理会计, 在之后的几十年内, 学者们纷纷对其展开了研究, 国 内企业也对管理会计在实践中的应用展开了探索。并 且管理会计在理论探索和实务发展方面都取得了一 定的成果。温素涁 (2020) 选取了 2000-2019 年国外 
知名会计期刊和国内《会计研究》作为研究对象，用 可视化分析的方法对国内外管理会计的研究进行了 分析, 分析得出我国学术界有关管理会计研究的侧重 点集中在公司治理、内部控制、平衡计分卡、经济增 加值、作业成本法、管理控制系统等这几个方面。随 着经济发展政策的变化, 我国管理会计研究在研究主 题与方法方面趋于宽口径多元化方向发展, 也越来越 得到学者们的重视。

管理会计的主要目标是通过向企业内管理者及 时提供决策有用信息, 从而帮助企业做出更好的经营 决策。具体来说管理会计可以为企业的成本计算与管 理、预算和绩效考核等方面提供决策信息, 从而帮助 企业做出更好的经营决策, 实现企业的价值增长。在 企业应用方面, 由于管理会计本身的职能特点, 可以 说管理会计具有极其重要的现实意义。当今 “一带一 路” 战略实施的的背景下, 企业的经营管理仅靠财务 会计已经得不到满足。为了应对更加复杂多变的外部 经营环境, 在更加激烈的国际竞争中立于不败之地, 管理会计的创新发展已经刻不容缓。在机遇与风险并 存的发展背景下, 我国管理会计要顺应时代发展潮流, 积极创新, 在与国外交流借鉴经验的过程中形成符合 中国国情的管理会计理论体系。企业也应当根据自身 的实际情况, 紧跟时代步伐将管理会计运用到企业的 日常经营管理中来, 从而使得企业更好的参与到国际 竞争中去。在 “一带一路” 背景下, 海尔集团改变了 自身的价值创造、流程管理以及服务理念。不再将财 务部门视作简单的交易处理者, 更是让其在企业的风 险管控和预绩效支持方面发挥作用。海尔更是建立起 基于 “业财税” 深度一体化的智能财务共享平台, 通 过财务共享平台的建设和智能化的技术运用实现了

“业财税” 三方面的有机结合。长时间以来企业的业 务流程、会计核算以及管理流程缺乏有效的手段连接 在一起, 而海尔集团通过财务共享中心将之连接在一 起, 使得管理会计在企业经营决策中发挥出应有的作 用。

\section{2. “一带一路”背景下我国管理会计发展遇 到的阻碍}

\subsection{1. 管理会计的理论体系与实践结合不够 紧密}

我国财政部自 2013 年以来颁布一系列指引政策 来推动中国管理会计体系的构建, 可以说是对管理会 计体系的构建给予了足够多的关注。目前来看, 我国 现阶段管理会计理论体系的构建还不够完善。部分学 者对此展开探讨。周国光 (2017) 从管理会计发展涉 及的相关理论问题和管理会计学构成内容两方面对 此展开了研究。他认为管理会计则是在利用财务会计 提供相关财务会计信息的基础上, 通过必要的整理、 归纳、加工与充实, 向单位内部管理层次提供对决策 与控制有用的财务成本信息。也有学者试图从不同的 角度对管理会计的理论体系进行创新与构建。丁胜红
和吴应宇（2019）创造性的提出了人本成本法, 试图 从人本经济发展观的角度来构建出管理会计理论体 系。总之, 从理论研究上来看, 这方面的研究还有所 欠缺, 学者们也未达成一致意见。“一带一路” 背景 下, 管理会计在企业中的应用变得更加重要, 亟需一 套完整成熟的理论体系来指导管理会计在实践中的 应用。经过近些年的发展, 我国管理会计在体系构建 方面已经取得了一定的成效。我国财政部会计司副司 长舒惠好在 2018 年由中国会计学会管理会计专业委 员会举办的学术年会上指出, 当前我国目前我国已经 基本建成由理论、指引、人才、信息化和咨询服务组 成的管理会计体系。管理会计理论体系在应用到实践 中时, 应当注意结合不同企业自身的业务特点以及自 身的战略定位和独特的经营管理模式。但是从实践来 看, 管理会计的理论体系在具体指导企业管理会计运 行方面仍存在问题, 需要进一步与实践结合才能更好 的指导企业发展进步。综合来看, 我国管理会计理论 体系的构建还需要各方面力量的共同推进, 将理论应 用到企业实践中来才能帮助企业实现战略目标, 促进 经济发展社会进步。

\subsection{2. 管理会计信息化程度尚未与“一带一路” 战略实施进程相匹配}

《指导意见》指出，信息化是管理会计体系建设 的重要支撑，单位应该将管理会计信息化纳入单位信 息化规划。管理会计信息化可以突破传统管理会计在 时间空间上的限制，获得企业在生产经营各个环节的 数据并且对此进行及时的传送与分析, 提高企业的经 营决策水平，最终达到提升企业价值的目的。管理会 计的信息化可以做到整合企业各个模块的资源, 以此 来推动企业管理会计不同环节的高效运作。在 “一带 一路” 战略实施以及互联网经济和相应的竞争全球化 背景下, 企业管理会计信息化显得尤为重要。当前阶 段, 我国企业管理会计信息化的程度还有待加强, 可 以说管理会计信息化在我国正处于初级发展阶段。管 理会计服务于企业的内部管理决策, 管理会计的创新 也要围绕企业的自身成长和价值创造。而在当前互联 网经济的背景下, 我国企业管理会计要想创新发展就 要加强信息化程度。很多企业尚未意识到管理会计发 展中信息化建设和财务共享应用的重要性, 这不利于 企业在日益激烈的竞争中建立起自己独特的竞争优 势, 甚至一定程度上会阻碍到我国管理会计信息化的 发展。而只有管理会计信息化得到发展, 我国管理会 计才能更好的在 “一带一路” 背景下助力我国企业在 日益激烈的国际化竞争中取得优势。目前看来我国企 业的管理会计信息化程度仍有较大发展空间, 只有少 数企业可以实现数字化, 还有企业内部各个管理会计 模块也没有完全联系起来, 造成财务信息与实际情况 不相符合的结果。在理论研究方面, 学者们也纷纷对 管理会计信息化展开探讨。目前学者们对管理会计信 息化的研究集中在其体系设计、应用以及与大数据等 相结合方面, 有待进一步研究。 


\subsection{3. 企业在经营管理中对管理会计缺乏足 够的重视}

“一带一路”的建设为我国企业的国际化提供了 良好的机遇，但是企业在国际化的过程中难免会遇到 由于外部复杂的经营环境所导致的经营风险, 为了降 低这种经营风险, 管理会计在企业日常经营活动中的 作用理应得到足够的重视。但由于一系列原因, 我国 相当一部分企业对管理会计的应用仍缺乏足够的重 视。一方面，企业的管理者没能正确的认识到传统的 财务会计与管理会计之间的差别, 往往只重视财务会 计而忽视管理会计应当发挥的作用。长久以来不利于 企业管理者掌握和了解企业自身的经营状况, 也不利 于企业在经营过程中做出科学合理的决策。另一方面, “一带一路” 背景下, 为了应对复杂多变的经营环境, 管理会计应当帮助企业进行决策前的信息处理数据 分析预测工作, 从而帮助企业更好的识别发展机遇应 对经营风险。然而相对于西方国家我国管理会计理论 实践起步都较晚, 大多数企业由于尚未对管理会计在 企业中的应用价值形成正确的认知, 仍处在传统的财 务会计阶段, 还未建立起专门的管理会计职能部门。 企业在经营管理中对管理会计的重视性不足不利于 企业在 “一带一路” 建设的大背景下抓住机遇走出国 门，也不利于我国管理会计的创新发展。

\section{2. 4. 高素质管理会计人才仍有很大缺口}

“一带一路” 战略实施的背景下, 企业走出国门 的同时对管理会计人才素质的要求也相应提高。管理 会计人才专业素质的高低可以说很大程度上影响着 企业的经营决策环节。一方面, 新的时代背景对应着 新的要求。当前, 企业的管理会计人员不仅应当熟练 掌握应用财务方面的知识技能, 还需要掌握经济学、 法律、外语以及计算机等方面的技能。只有这样, 企 业的管理会计人员才可以为企业经营管理决策提供 有用的数据分析和决策参考。而当前很多企业的管理 会计人员由于本身知识技能的欠缺, 并不能通过自身 的工作很好的为企业价值创造做出贡献, 这不利于我 国管理会计的发展进步。当前 “互联网+” 背景下, 企 业管理信息化的推动以及财务共享中心的构建更是 需要专业的人才为之提供专业服务, 我国在这一方面 的人才仍有很大缺口。另一方面, 从管理会计人才培 养环节来看, 我国高校在人才培养过程中由于专业课 程设置和教师企业经历缺乏等原因, 学生的知识技能 往往局限于书本专业知识, 很难将所学理论应用到之 后的实践中去。这对不利于高素质管理会计专业人才 的培养。企业在管理会计人才的后续培训以及继续教 育方面也存在一定的不足。当前我国很多企业对管理 会计应用存在着思想上的滞后性, 没有形成自己的管 理会计人才培训体系, 这不利于 “一带一路” 背景下 企业的跨国合作与交流。

\section{4. “一带一路” 背景下推动我国管理会计发展 的对策及建议}

\section{1. 进一步推动管理会计理论体系与实践相 结合}

自 2013 年 “一带一路” 战略实施以及之后财政 部陆续颁布的一系列政策以来, 我国管理会计理论体 系的建立相较之前已经取得了很大的进步。但是从理 论研究和在我国企业具体实践中看来, 仍需进一步完 善, 并且需要采取措施来加强其与企业实践的联系程 度。使得管理会计理论体系能够真正起到指引实践并 且达到为企业创造价值的目标。一方面，政府应该采 取措施大力支持相关的科研工作, 激励学者们踊跃创 新, 充分利用好 “一带一路” 这个平台, 借鉴国外管 理会计研究理论来对我国的理论展开新的探索与思 考。从而进一步完善我国的管理会计理论体系。企业、 学术研究人员充分利用 “一带一路” 战略背景下我国 同世界其他国家的交流，借助丰富的管理会计理论和 实务研究内 容, 完善我国的管理会计理论体系; 另 一方面, 管理会计理论体系完善的最终目的还是为了 更好的指导管理会计在企业中的应用实践。管理会计 在企业中的应用要结合大的时代背景, 充分了解由于 国家政策等所导致的外部经营环境变化, 让管理会计 成为帮助企业科学进行经营决策的工具。企业在实际 应用中还应对传统的财务会计与管理会计做出正确 的划分。并且根据企业自身所处的行业、地区以及自 身独特的经营管理特点来创新性的将管理会计理论 体系与实践结合起来。

\section{2. 抓住 “一带一路” 平台机遇, 加快实现我 国管理会计信息化进程}

2015 年我国财政部发布《关于全面推进管理会计 体系建设的指导意见》, 该意见鼓励我国大型企业和 企业集团的单位建立财务共享服务中心。“一带一路” 战略的实施以及互联网大数据技术的应用为我国管 理会计信息化发展提供了良好的机遇。熊磊（2015） 认为财务共享可以视作企业会计信息化建设的重要 组成部分, 可以帮助企业实现财务数据在各个环节的 共享。可以说财务共享中心的建立可以促进我国管理 会计信息化建设的发展。因此我们应该顺应 “一带一 路” 发展趋势, 鼓励我国企业建立财务共享中心, 推 动管理会计信息化的进程。在企业构建财务共享中心 的基础上, 借助大数据等技术, 让管理会计在企业的 整个生产经营过程中发挥作用, 推动我国管理会计的 创新发展。这也有利于 “一带一路” 背景下我国企业 更好的参与到国际竞争中去。2016 年财政部在《管理 会计基本指引》中明确要求企业进行业务与财务的融 合发展。“一带一路” 以及 “互联网+” 的背景下, 企业的业务与财务的有机融合有利于管理会计更好 的为企业经营决策提供参考, 使得信息数据共享在企 业内部得以实现。因此, “一带一路” 背景下企业还应 
当注意业务与财务二者的有机融合。当然，随着企业 内部信息数据流通的增加, 信息安全也应该成为企业 的关注对象, 企业也应当投入一定的精力来维护信息 安全。

\section{3. 提高企业在日常经营中对管理会计的重 视程度}

管理会计在企业经营决策中所起的作用冊庸置 疑，但目前来看企业内部对管理会计仍然缺乏足够的 关注和重视。为了应对 “一带一路” 战略实施为企业 带来的更加复杂多变的经营环境, 企业应当在日常生 产经营中给予管理会计足够的重视。在管理会计岗位 设置上与财务会计进行区分, 保证管理会计在企业业 务运作中的地位。从而让员工也认识到管理会计的重 要性, 激励他们完成传统财务会计人员向新时代管理 会计人员的转变。只有这样才能推动管理会计的发展, 提高我国企业在国际上的竞争力。另一方面, “一带 一路” 战略的实施为我国管理会计发展提高良好的平 台, 我国企业与沿线国家间的经济贸易往来也日趋密 切。这种背景下若向在竞争中立于不败之地, 管理会 计的应用必须得到足够的重视。这也要求企业的管理 会计人员认识到提升自我专业素质的重要性, 专注于 自身管理会计专业能力的提升, 积极主动的参与到我 国管理会计的发展中来。

\section{4. 培养高素质管理会计人才, 助力“一带一 路”建设}

“一带一路”战略的实施对我国管理会计人才的 综合素质提出了更高的要求。我国应该顺应 “一带一 路” 建设的潮流加快培养出一批国际化的具有较高综 合素质的管理会计人才。范英杰 (2019) 提出高校可 以通过国际融合式教育以及改革课程内容和教学方 式来培养出服务于 “一带一路” 发展战略的国际化会 计人才。一方面, 国内高校应当在课程设置中对管理 会计这门学科给予足够高的重视程度。并且注重理论 学习与管理会计应用实践的教学, 具体可以通过与企 业对接, 建立起合作关系实现双赢。此外高校会计专 业还要注意培养掌握多门知识的复合型会计人才。只 有这样才能培养出一批适应 “一带一路” 背景的具备 管理会计职业素养的优秀管理会计人才。另一方面, 从企业的角度来看, 企业应当恰当处理好管理会计与 财务会计的关系，给予管理会计岗位明确的职责划分, 而不是采取模棱两可的态度。企业要做好对管理会计 人才的技能培训工作, 采取恰当的激励措施来充分调 动企业管理会计人员的学习积极性。可以借助 “一带 一路” 战略所带来的机遇, 给优秀员工参与海外培训 的机会, 从而更好的实现管理会计人才国际化, 提升 他们的综合素质。企业还应当注重会计员工的继续教 育工作, 会计作为一门与经济发展情况息息相关的学 科, 相应的会计人员应该树立终身学习的理念。通过 企业会计人员的再教育使之适应 “一带一路” 发展的
大趋势，从而提高企业自身的管理会计应用水平。最 后，“一带一路” 背景下管理会计人员本身也要注重 自身专业技能水平的提高，不能将自身的知识技能局 限于传统的财务会计。管理会计人员要努力提升自己 的格局, 学习与会计学科相关的一系列知识技能如计 算机、法律等。参与到 “一带一路” 建设中, 还要积 极主动了解合作国家的经济文化以及法律税收方面 的差异, 从而帮助企业走向国际舞台的时候更好的规 避经营风险。

\section{5. 结论}

“一带一路”战略的实施为我国企业的国际化发 展和管理会计的发展都带来了前所未有的机遇。企业 在走出国门的同时不可避免的要应对与机遇并存的 风险。为了更好的抓住机遇规避风险, 企业应当重视 管理会计在企业经营活动中的应用。“一带一路” 战 略实施以来, 随着相关政策的出台以及各方的努力, 我国管理会计理论体系也得到了进一步的发展。在实 践应用方面也取得了相应的成果。相信不久的将来, 我国管理会计发展水平必将得到更好的发展。

\section{REFERENCES}

[1] Lianfeng, Z., Danko, Y., \& Zhuanqing, C. (2020). International cooperation of ukraine tourism based on "the belt and road initiative". Accounting and Finance, 3:140-147.

[2] Duh, R. R., Xiao, J. Z., \& Chow, C. W. (2007). An overview and assessment of contemporary management accounting research in china. Journal of Management Accounting Research, 20: 870-881.

[3] Haverty, John, \& L. (2007). Management control of multinational enterprises in china: a contracting and management accounting perspective. Journal of International Accounting Research, 6: 114-115.

[4] Yang, S., Yu, J., \& Wang, X. (2016). Discussing on Management Accounting Application and Promotion in the Chinese Administrative Units. In: Annual International Conference on Accounting and Finance. Ottawa. pp.15-17.

[5] Taipaleenm, Ki, J., \& Ik Heimo, S. (2013). On the convergence of management accounting and financial accounting - the role of information technology in accounting change. International Journal of Accounting Information Systems, 14: $321-348$ 